\title{
Distinct Changes in Cortical Acetylcholine and Noradrenaline Efflux during Contingent and Noncontingent Performance of a Visual Attentional Task
}

\author{
Jeffrey W. Dalley, ${ }^{1}$ Jill McGaughy, ${ }^{1}$ Mark T. O’Connell,, ${ }^{2}$ Rudolf N. Cardinal, ${ }^{1}$ Liat Levita, ${ }^{1}$ and \\ Trevor W. Robbins ${ }^{1}$ \\ ${ }^{1}$ Department of Experimental Psychology, University of Cambridge, Cambridge, United Kingdom CB2 3EB, and \\ 2Academic Department of Neurosurgery and Wolfson Brain Imaging Centre, University of Cambridge, Addenbrooke's \\ Hospital, Cambridge, United Kingdom CB2 2QQ
}

Optimization of cognitive processing may depend on specific and distinct functions of the cortical cholinergic and noradrenergic systems. This investigation dissociates functions of cortical acetylcholine (ACh) and noradrenaline (NA) in arousal and visual attention by simultaneously measuring ACh and NA efflux in the rat prefrontal cortex during sustained attentional performance. The five-choice serial reaction time task was used to provide a continuous assessment of visuospatial attention. Previous studies using this task have established a critical role for the cortical cholinergic system in the detection of visual targets. However, selective lesions of the locus coeruleus noradrenergic system impair performance only when additional attentional demands are placed on the subject by distractors or temporally unpredictable targets. To test the hypothesis that the cortical noradrenergic system is particularly sensitive to novel task contingencies, we also assessed NA and ACh efflux in rats that been trained previously on the task but for whom the instrumental contingency coupling responding with stimulus detection and reward was abolished. Cortical ACh efflux showed a robust and task-related increase during established contingent performance. This response was significantly attenuated in noncontingent subjects, although it still exceeded pretask values. In contrast, NA efflux only increased transiently in contingent subjects after task onset but showed sustained elevations in noncontingent subjects on the first day when contingencies were changed. These data also implicate cortical ACh in aspects of attentional functioning but highlight a specific involvement of the cortical noradrenergic system in detecting shifts in the predictive relationship between instrumental action and reinforcement.

Key words: cognition; attention; arousal; in vivo microdialysis; prefrontal cortex; instrumental contingency learning
Cortically projecting noradrenergic and cholinergic systems have been widely implicated in arousal and visual attention (AstonJones and Bloom, 1981; Voytko et al., 1994; Robbins, 1997; Sarter and Bruno, 2000). Previous studies have highlighted a role for the locus coeruleus (LC) noradrenergic system in the selective attention of salient unexpected stimuli. Thus, LC neurons show increased activity to multimodal sensory stimuli (Aston-Jones and Bloom, 1981; Rasmussen and Jacobs, 1986), and various stimuli, including novelty, increase noradrenaline (NA) efflux in the frontal cortex (Dalley et al., 1995; Feenstra, 2000). In contrast, the cortical cholinergic system has been hypothesized to subserve primary aspects of attentional processing, including stimulus detection and response selection (Robbins, 1997; Passetti et al., 2000; Sarter and Bruno, 2000).

Previous experiments using an attentional task designed to assess aspects of sustained and spatially divided attention ("the five-choice serial reaction time task") have shown that discrimi-

\footnotetext{
Received Jan. 17, 2001; revised March 22, 2001; accepted April 16, 2001.

This work was supported by a Programme grant from the Wellcome Trust. It was completed within the Medical Research Council (MRC) Cooperative in Brain, Behavior, and Neuropsychiatry. J.M. was supported by a fellowship from the Human Frontier Science Program Organization. R.N.C. and L.L. were supported by research studentships from the MRC (UK) and Wellcome Trust, respectively, and by a James Baird award from the University of Cambridge School of Clinical Medicine (R.N.C.).

Correspondence should be addressed to Dr. Jeffrey W. Dalley, Department of Experimental Psychology, Downing Street, University of Cambridge, Cambridge, UK CB2 3EB. E-mail: jwd20@cus.cam.ac.uk.

Copyright (C) 2001 Society for Neuroscience $0270-6474 / 01 / 214908-07 \$ 15.00 / 0$
}

native accuracy depends on the integrity of the cortical cholinergic system (Muir et al., 1993, 1994). However, relatively selective lesions of the LC noradrenergic system impaired performance only under arousing conditions when distracting stimuli were present or when target stimuli were made temporally unpredictable (Carli et al., 1983; Cole and Robbins, 1992). These findings suggest that the LC noradrenergic system preserves attentional selectivity in a novel environment in which behavior needs to be more flexible and less prone to discriminative errors (Robbins, 1997; Usher et al., 1999). The demonstration that LC neurons also increase activity during reversal or extinction of a Pavlovian conditioning task also supports this proposal (Sara and Segal, 1991).

In this study, in vivo microdialysis was used to measure acetylcholine (ACh) and NA influx into the prefrontal cortex of rats performing a five-choice serial reaction time task (Carli et al., 1983), which requires the continuous detection of brief but spatially unpredictable visual stimuli. Two experimental manipulations were used. The first, an attentional performance group, confirmed and extended our recent findings of increased cortical ACh efflux after task onset (Passetti et al., 2000) by concurrently determining NA and ACh efflux in the same subject. The second manipulation degraded the instrumental contingency inherent in the task by making reinforcement contingent on the performance of a second animal. Subjects in this group could thus engage in the task and receive the same number of rewards as their yoked controls but were no longer rewarded for correct responses. On 
the basis of a previous study (Balleine and Killcross, 1994), we expected rats to shift responding from the visual discriminanda to the food source. We predicted that this shift would be accompanied by a reduction in stimulated cortical ACh efflux on the hypothesis that such changes depend on aspects of performance distinct from simple consummatory behavior (Passetti et al., 2000). An additional prediction based on previous hypotheses of LC noradrenergic function (Usher et al., 1999) is that cortical NA efflux would be sensitive to changing instrumental contingencies when attention has to be redirected toward stimuli that more accurately predict reward delivery.

\section{MATERIALS AND METHODS}

Subjects. The subjects were 20 male Lister hooded rats (Harlan Olac, Bicester, UK) weighing between 280 and $320 \mathrm{gm}$ before behavioral training. They were housed in pairs until surgery and then alone under temperature-controlled conditions and an alternating $12 \mathrm{hr}$ light/dark cycle (lights off from 7:30 A.M. until 7:30 P.M.). Rats received water ad libitum and $16 \mathrm{gm}$ of laboratory chow once daily. All experiments were conducted in strict accordance with the UK Animals (Scientific Procedures) Act of 1986.

Apparatus. A detailed description of the nine-hole apparatus has been provided previously (Carli et al., 1983). Briefly, four $25 \times 25 \mathrm{~cm}$ boxes were used (Paul Fray Ltd., Cambridge, UK); each box was placed in a ventilated sound-attenuating chamber and illuminated by a $3 \mathrm{~W}$ bulb. At the front of the box, a magazine connected with a food dispenser was present, with access provided by a Perspex panel. At the rear of the box were five apertures with infrared photocell beams at the entrance to detect nosepoke responses. The apparatus was controlled by software written by R. N. Cardinal in Arachnid (Paul Fray Ltd.), a real-time extension to $\mathrm{BBC}$ Basic $\mathrm{V}$ running on an Acorn (Cambridge, UK) Archimedes series computer.

Behavioral training. Animals were trained on the five-choice serial reaction time task to a stable level of performance as described previously (Granon et al., 2000). This was achieved over 37 daily sessions, each session consisting of 100 trials lasting $\sim 30 \mathrm{~min}$. Briefly, animals were trained to respond to brief flashes of light presented randomly in one of five spatial locations. Correct responses were rewarded with a small food pellet (Noyes dustless pellets, $45 \mathrm{mg}$; Sandown Scientific, Middlesex, UK), whereas incorrect, premature, and perseverative responses were punished by no food being delivered in the magazine and the house light being extinguished for $5 \mathrm{sec}$. Once asymptotic performance had been reached $(>80 \%$ accuracy, $<20 \%$ omissions, stimulus duration of $0.5 \mathrm{sec}$ ), animals were switched to a modified version of the task whereby time-out periods were no longer punished by the house light being extinguished. In addition, incorrect and omitted responses served to reset automatically the intertrial interval (ITI) $(5 \mathrm{sec})$. As before, subjects were required to collect their food reward if a correct response was made to start the next trial. Rats were taken for surgery after an additional training period of at least 37 daily sessions to re-establish asymptotic performance.

Experimental design. Trained rats were randomly assigned to two performance groups ("contingent" or "noncontingent") $7 \mathrm{~d}$ before surgery. The selection of animals in each group was counterbalanced across the four operant boxes. Baseline behavioral measures during contingent performance were recorded on 7 consecutive days before surgery to ensure that both groups were evenly matched. The dependent variables measured were choice accuracy (number of correct responses divided by the total number of correct and incorrect responses), omissions, correct response latency, magazine latency, perseverative panel pushes, and premature responses. After surgery, and on day 1 of the microdialysis experiment, contingent animals continued to perform the task as previously trained. Noncontingent animals received the same visual stimuli and food rewards as their paired contingent subjects, but their actions led to no programmed consequences. At the end of the experiment, the inlet and outlet lines of the dialysis probe were plugged and the animals were returned to their home cage. The experiment was repeated the next day at approximately the same time.

Surgical procedures. Rats were anesthetized with ketamine (Ketalar, 90 $\mathrm{mg} / \mathrm{kg}$, i.p.; Vet Drug, Bury St. Edmunds, UK) and xylazine (Rompun, $6.7 \mathrm{mg} / \mathrm{kg}$, i.p.; Vet Drug) and secured in a stereotaxic frame in a flat skull position. Concentric-design microdialysis probes [for construction details, see Dalley et al. (1998)] with $2 \mathrm{~mm}$ active membranes (Fitral 16; Hospal, Rugby, UK) were implanted in the prelimbic region of the prefrontal cortex $(\mathrm{Cg} 3)$, counterbalanced by cerebral hemisphere, at $12^{\circ}$ to the perpendicular using standard stereotaxic techniques. The coordinates used were: anteroposterior, $+3.0 \mathrm{~mm}$ bregma; lateral, $\pm 1.2 \mathrm{~mm}$ from the midline; and dorsoventral, $-4.0 \mathrm{~mm}$ from the dural surface (Paxinos and Watson, 1982). The in vitro recoveries of NA and ACh at $2 \mu \mathrm{l} / \mathrm{min}$ were $11.1 \pm 0.8 \%(n=5)$ and $12.7 \pm 0.5 \%(n=5)$, respectively. The probe was filled with artificial CSF (aCSF) (see below for composition details) and secured on the skull, adjacent to a plastic tethering post $(4 \mathrm{~mm}$ diameter $\times 10 \mathrm{~mm}$ length), using three bone screws and dental cement. After surgery, rats were housed individually and allowed $48 \mathrm{hr}$ to recover before the microdialysis experiments. On the first recovery day, rats were given $30 \mathrm{gm}$ of food, whereas on the second recovery day, food was restricted to $16 \mathrm{gm}$ each.

Microdialysis procedures. Animals were placed in the nine-hole box and connected to a counterbalanced spring tether to allow the inlet and outlet lines to be connected to the dialysis probe. The probe was connected to a dual-channel liquid swivel (Instech; Biotech Instruments Ltd., Hitchin, $\mathrm{UK}$ ) and perfused at $2 \mu \mathrm{l} / \mathrm{min}$ with aCSF containing (in mM): $147 \mathrm{NaCl}$, $3 \mathrm{KCl}, 1 \mathrm{MgCl}_{2}, 1.3 \mathrm{CaCl}_{2}, 1.3 \mathrm{Na}_{2} \mathrm{HPO}_{4}$, and $0.2 \mathrm{NaH}_{2} \mathrm{PO}_{4} \cdot \mathrm{H}_{2} \mathrm{O}, \mathrm{pH}$ 7.4. The perfusate contained a low concentration $(50 \mathrm{nM})$ of the cholinesterase inhibitor neostigmine to augment levels of ACh in the dialysate fluid. Six $10 \mathrm{~min}$ basal samples were collected $1 \mathrm{hr}$ after probe connection. An additional six samples were collected during task performance. Samples were stored on dry ice and then at $-85^{\circ} \mathrm{C}$ before being analyzed for NA and ACh content. At the conclusion of the microdialysis experiment, animals were administered a sublethal injection of phenobarbitone (Euthatal; Vet Drug) and transcardially perfused with $0.1 \mathrm{M}$ phosphate buffer followed by $4 \%$ paraformaldehyde. Brains were stored in $4 \%$ paraformaldehyde for $24 \mathrm{hr}$ and then transferred to a $30 \%$ sucrose solution before sectioning and staining with cresyl violet to determine the precise position of the probe in the medial prefrontal cortex.

Analytical methods. NA and ACh were determined in brain samples using HPLC and electrochemical detection (ECD). NA was analyzed as described previously (Dalley et al., 1998), except that samples were automatically injected (Gilson 234 autosampler; Anachem, Luton, UK). The detection limit for NA was $2 \mathrm{fmol} / 10 \mu \mathrm{l}$ injection, and the response was linear over at least a 100-fold range. The analysis of ACh was based on a previous method (Huang et al., 1995), with the mobile phase containing $75 \mathrm{mM} \mathrm{Na}_{2} \mathrm{HPO}_{4}$ and $5 \mathrm{ml} / 1$ ProClin reagent (BAS, Congleton, $\mathrm{UK}$ ), $\mathrm{pH} 8.0$ (adjusted with $46 / 48 \% \mathrm{NaOH}$ ), and a flow rate of 120 $\mu \mathrm{l} / \mathrm{min}$ (582 solvent delivery module; ESA Inc., Chelmsford, MA). Samples were injected manually (UniJet microbore valve; BAS) onto a microbore analytical column $(530 \times 1 \mathrm{~mm}, 10 \mu \mathrm{m}$; BAS $)$. A microbore post-column enzyme reactor $(50 \times 1 \mathrm{~mm}$; Chrompack, United Kingdom Ltd., London, UK) containing choline oxidase and acetylcholinesterase was used to convert $\mathrm{ACh}$ and choline to hydrogen peroxide before detection across a perioxidase-wired glassy carbon electrode (UniJet 3 $\mathrm{mm}$ cell; BAS) held at $0 \mathrm{mV}$ relative to a platinum reference electrode (Petit Ampere controller; BAS). All components of the HPLC-ECD system (except the pump and mobile phase) were housed within a temperature-controlled environment set at $28^{\circ} \mathrm{C}$. The detection limit for ACh under these conditions was $\sim 2 \mathrm{fmol} / 5 \mu \mathrm{l}$ injection.

Data analyses. All analyses were conducted using SPSS for Windows (version 9.0; SPSS, Chicago, IL). The baseline behavioral data were analyzed by two-way ANOVA with one between-subject factor, group (contingent, noncontingent), and one repeated within-subject factor, day (seven daily $30 \mathrm{~min}$ test sessions). The behavioral data collected during the microdialysis test sessions were subjected to three-way ANOVA with one between-subject factor, group (contingent, noncontingent), and two repeated within-subject factors, time $(12 \times 5$ min bins) and day (day 1 , day 2). Significant interactions were then evaluated by ANOVA. The dialysis data are expressed as a percentage of the last three baseline samples and were analyzed using three-way ANOVA with one betweensubjects factor, group, and two repeated within-subjects factors, day (day 1, day 2) and time (final basal sample and six consecutive 10 min samples during performance). Where appropriate, a Dunnett's $t$ test was used for pair-wise comparisons between basal (final sample) and task-related values. Differences in basal efflux were assessed over the last three basal samples using ANOVA with the following factors: group, day, and time (three consecutive 10 min samples). 
Table 1. Baseline performance of future contingent and noncontingent subjects on the five-choice serial reaction time task

\begin{tabular}{lccll} 
& Contingent subjects & Noncontingent subjects & Group & Day \\
\hline Correct responses & $77 \pm 1$ & $78 \pm 1$ & $F_{(1,18)}=0.03 ; p=0.88$ & $F_{(6,108)}=1.45 ; p=0.20$ \\
Choice accuracy $(\%)$ & $86.9 \pm 1.2$ & $87 \pm 0.4$ & $F_{(1,18)}=0.01 ; p=0.98$ & $F_{(6,108)}=0.63 ; p=0.71$ \\
Omissions & $12 \pm 1$ & $12 \pm 1$ & $F_{(1,18)}=0.01 ; p=0.96$ & $F_{(6,108)}=2.25 ; p=0.06$ \\
Correct latencies (csec) & $51.2 \pm 0.7$ & $51.8 \pm 0.6$ & $F_{(1,18)}=0.10 ; p=0.76$ & $F_{(6,108)}=0.76 ; p=0.60$ \\
ITI magazine entries & $76 \pm 3$ & $77 \pm 3$ & $F_{(1,18)}=0.01 ; p=0.97$ & $F_{(6,108)}=0.21 ; p=0.97$ \\
Premature responses & $9 \pm 0.5$ & $9 \pm 0.5$ & $F_{(1,18)}=0.03 ; p=0.87$ & $F_{(6,108)}=0.68 ; p=0.67$
\end{tabular}

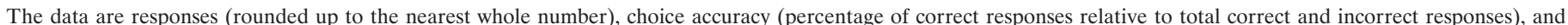

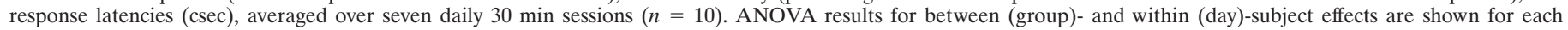
behavioral variable.

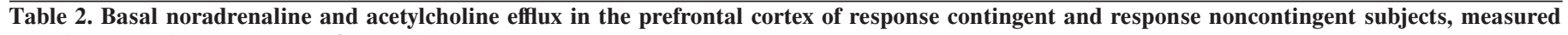
over 2 consecutive days on the five-choice task

\begin{tabular}{|c|c|c|c|c|c|c|c|}
\hline & \multicolumn{2}{|c|}{ Contingent subjects } & \multicolumn{2}{|c|}{ Noncontingent subjects } & \multirow[b]{2}{*}{ Group } & \multirow[b]{2}{*}{ Day } & \multirow[b]{2}{*}{ Time } \\
\hline & Day 1 & Day 2 & Day 1 & Day 2 & & & \\
\hline NA & $5.21 \pm 0.57$ & $5.49 \pm 0.53$ & $5.10 \pm 0.53$ & $5.04 \pm 0.52$ & $F_{(1,18)}=0.22 ; p=0.65$ & $F_{(1,18)}=0.05 ; p=0.82$ & $F_{(2,36)}=0.64 ; p=0.53$ \\
\hline $\mathrm{ACh}$ & $244.9 \pm 26.8$ & $219.7 \pm 29.2$ & $256.9 \pm 43.3$ & $210.1 \pm 26.7$ & $F_{(1,18)}=0.01 ; p=0.95$ & $F_{(1,18)}=1.64 ; p=0.22$ & $F_{(2,36)}=0.28 ; p=0.76$ \\
\hline
\end{tabular}

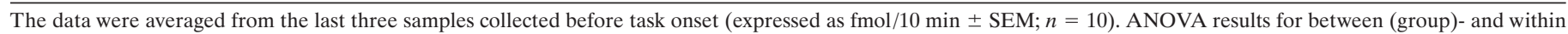
(day, time)-subject effects are shown for each neurotransmitter.

\section{RESULTS}

\section{Baseline behavior}

Table 1 shows the baseline performance of future contingent and noncontingent subjects on the five-choice serial reaction time task, collapsed over seven consecutive daily sessions. ANOVA revealed no significant main effects of group or day on the number of correct responses, choice accuracy, omission rate, correct response latency, ITI magazine entries, or premature responses; no significant interactions were observed either. Therefore, before surgical intervention both sets of animals achieved the same asymptotic level of performance on the task and were evenly matched.

\section{Probe location}

The microdialysis probes were all located predominantly within the prelimbic region of the medial prefrontal cortex $(\mathrm{Cg} 3)$ (Zilles, 1985), $\sim 3.0-3.5 \mathrm{~mm}$ forward to bregma. In no cases were probes located within the infralimbic cortex. However, careful reconstruction of the tracks revealed that most probes also sampled the ventral-most aspect of $\mathrm{Cg} 1$. A representative probe track within the medial prefrontal cortex is shown in a recently published study (Passetti et al., 2000).

\section{Cortical NA and ACh efflux during task performance}

Absolute basal levels of NA and ACh before task onset are given in Table 2. Overall, there were no main effects of group, day, or time on these levels.

The effect of degrading the instrumental contingency of the five-choice task on levels of extracellular NA in the prefrontal cortex is shown in Figure 1. This procedure resulted in a rapid and sustained increase in cortical NA efflux in noncontingent subjects on the first day. Analysis of the group-by-day interaction $\left(F_{(1,18)}=4.89 ; p=0.04\right)$ revealed that cortical NA levels were significantly greater in noncontingent subjects on day 1 (group: $\left.F_{(1,18)}=9.61 ; p<0.01\right)$ but were unchanged relative to contingent subjects on day 2 (group: $F_{(1,18)}=0.38 ; p=0.55$ ). Contingent performance on the task was associated with more variable changes in cortical NA efflux. On the first day, NA efflux increased
DAY 1

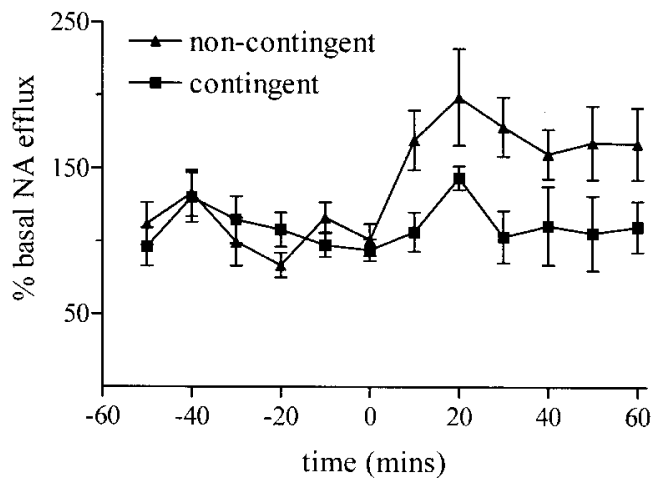

DAY 2

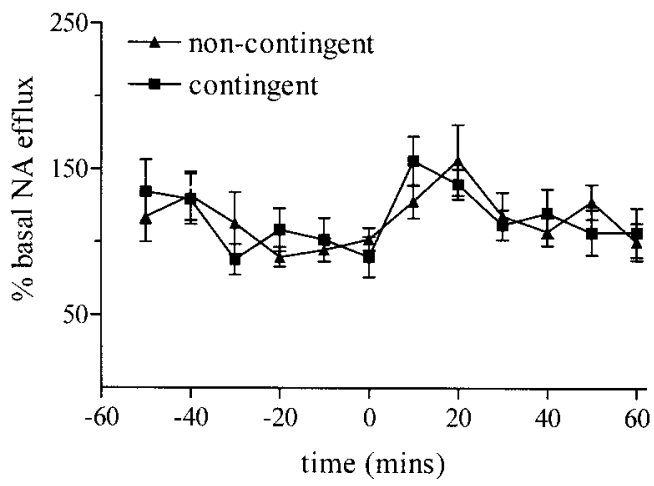

Figure 1. Changes in extracellular levels of noradrenaline in rat prefrontal cortex during contingent and noncontingent performance of a fivechoice serial reaction time task. Contingent animals $(n=10)$ and their yoked counterparts $(n=10)$ were run on the task over two consecutive daily sessions. The task was initiated after a $1 \mathrm{hr}$ baseline collection period at a time of $0 \mathrm{~min}$. The data are expressed as a percentage of the mean basal efflux $( \pm$ SEM; $n=10)$. 
DAY 1

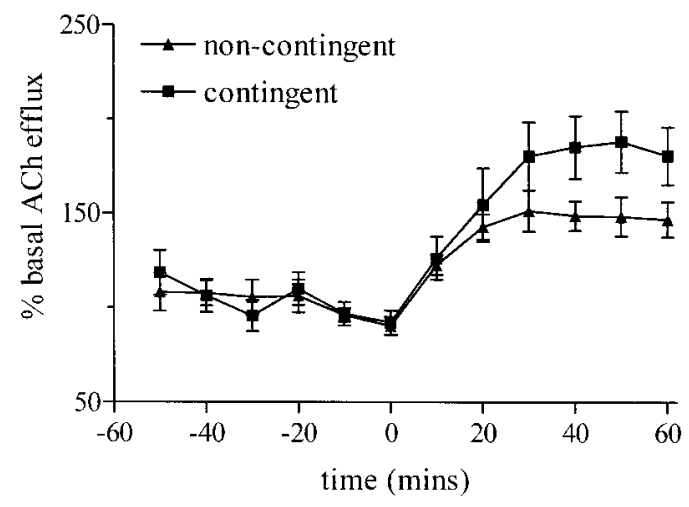

DAY 2

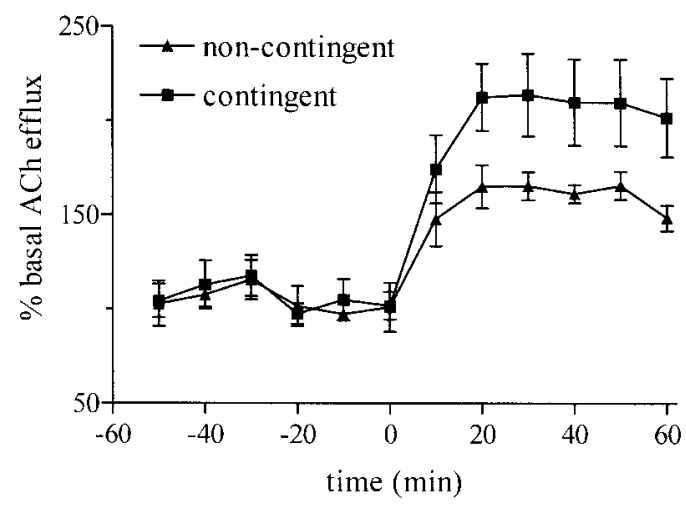

Figure 2. Changes in extracellular levels of acetylcholine in rat prefrontal cortex during contingent and noncontingent performance of a fivechoice serial reaction time task. The task was initiated (at a time of $0 \mathrm{~min}$ ) after a $1 \mathrm{hr}$ baseline collection period. The data are expressed as a percentage of the mean basal efflux $( \pm \mathrm{SEM} ; n=10)$.

transiently after task onset, but this was not significant relative to the final pretask sample. In contrast, on the second day the initial increase in cortical NA efflux (0-10 min) was significant relative to the final basal sample $(p<0.05)$. However, this increase was transient, with levels declining to pretask levels during further performance on the task.

Figure 2 shows the effects of contingent and noncontingent performance of the task on extracellular levels of $\mathrm{ACh}$ in the prefrontal cortex. After task onset, cortical ACh efflux increased in both groups by $\sim 150-200 \%$ relative to pretask levels. This response was significantly greater in contingent animals (group: $F_{(1,18)}=9.74 ; p<0.01$ ) over the course of both days (group by day: $\left.F_{(1,18)}=0.09 ; p=0.77\right)$.

Therefore, an abolition of the instrumental contingency of a five-choice serial reaction time task leading to responseindependent rather than response-dependent reinforcement produced differential effects on NA and ACh release in the prefrontal cortex. These data highlight a specific involvement of cortical $\mathrm{ACh}$ in aspects of established instrumental performance on this task. In contrast, the cortical NA system appears to be especially engaged by a shift in the instrumental contingency rather than by established response-contingent performance.

\section{Behavior during in vivo microdialysis}

Table 3 summarizes the performance of contingent subjects on the five-choice task over the 2 consecutive test days. Contingent subjects maintained a stable level of performance in terms of the total number of trials completed, the number of correct trials, choice accuracy, omissions, and correct latencies (all $F<1$ ). Premature responses declined during each session on both days $\left(F_{(2,18)}=7.24 ; p<0.01\right)$.

Figure 3 shows the comparative effects of degrading the instrumental contingency on the behavior of contingent and noncontingent subjects on the five-choice task. Analysis of total correct responses revealed main effects of group $\left(F_{(1,18)}=48.87 ; p<\right.$ $0.01)$ and time $\left(F_{(11,198)}=5.61 ; p<0.01\right)$ as well as a significant group-by-day interaction $\left(F_{(1,18)}=11.83 ; p<0.01\right)$. Thus, on both days noncontingent subjects made fewer correct responses than contingent subjects. In addition, noncontingent subjects made fewer correct responses on day 2 than day $1\left(F_{(1,9)}=39.84\right.$; $p<0.01)$, whereas correct responses for contingent subjects remained constant over both days $\left(F_{(1,9)}=0.685 ; p=0.429\right)$. These data show that contingent animals maintained a stable level of performance over both days, whereas noncontingent animals showed a progressive decline in responding for target stimuli. However, on trials in which noncontingent subjects made a response, they did so as accurately as their contingent partners $\left(F_{(1,18)}=1.169 ; p=0.294\right)$, with a similar correct latency $\left(F_{(1,18)}\right.$ $=0.163 ; p=0.691)$.

Magazine entries were almost twice as frequent in noncontingent animals compared with contingent subjects (group: $F_{(1,18)}=$ 29.8; $p<0.01$ ). This behavior showed a clear tendency to decline by the latter half of the second day session. Analysis of premature responses revealed main effects of day $\left(F_{(1,18)}=16.615 ; p<0.01\right)$ and time $\left(F_{(11,198)}=4.822 ; p<0.01\right)$ and an interaction between day and group $\left(F_{(1,18)}=5.119 ; p<0.05\right)$. Additional analysis of this interaction showed that noncontingent animals made more

Table 3. Behavioral measures of contingent performance on the five-choice serial reaction time task assessed concurrently with in vivo microdialysis over 2 consecutive days

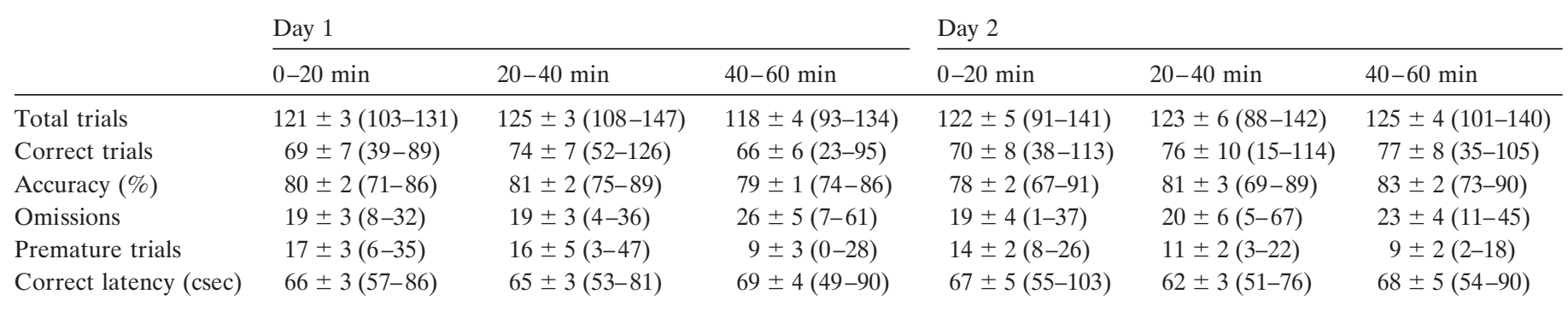

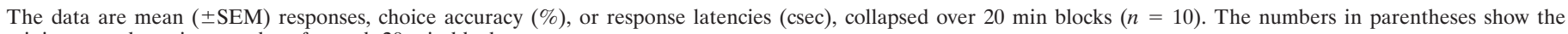
minimum and maximum values for each 20 min block. 
DAY 1

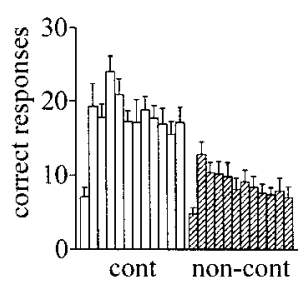

DAY 1

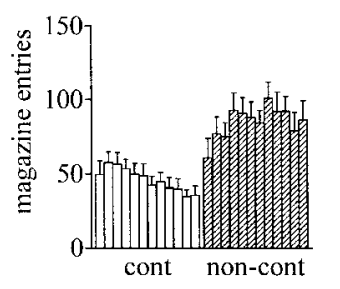

DAY 1

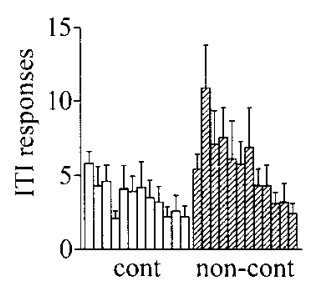

DAY 2
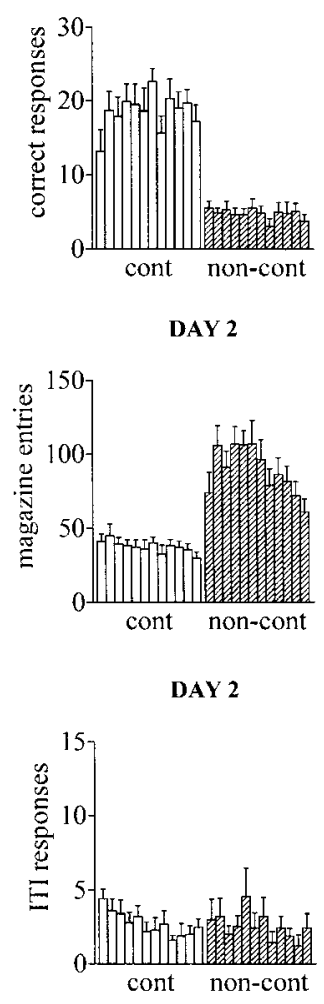

Figure 3. Behavioral performance of contingent and noncontingent subjects on the five-choice serial reaction time task over 2 consecutive days of testing. During the experiment, animals were head-tethered to a counterbalanced spring support to allow the simultaneous application of in vivo microdialysis during task performance. The stimulus duration and intertrial interval were 50 and $500 \mathrm{csec}$, respectively. Each bar represents successive $5 \mathrm{~min}$ bins over $1 \mathrm{hr}$ ( $\pm \mathrm{SEM} ; n=10)$ for contingent (white bars) and noncontingent (striped bars) subjects. It can been seen that animals in the contingent group maintained a stable level of performance over both days, whereas noncontingent subjects extinguished responding for target stimuli and made more anticipatory responses and magazine entries.

premature responses on day 1 than day $2\left(F_{(1,9)}=14.99 ; p<\right.$ $0.01)$, whereas contingent animals exhibited a similar profile of premature responding on both days $\left(F_{(1,9)}=2.491 ; p=0.149\right)$.

Overall, these behavioral data show that noncontingent subjects very rapidly extinguish responding for target stimuli and direct more activity toward the food source. On the second day of exposure to a shift in the instrumental contingency, these subjects exhibit more organized behavior with fewer premature responses and fewer surplus magazine entries to retrieve food pellets.

\section{DISCUSSION}

This investigation is the first to measure simultaneously ACh and NA efflux in rat prefrontal cortex during performance of a visuospatial attentional task. The main finding was that cortical NA efflux showed the greatest increase when the contingency changed from response-dependent to response-independent reinforcement. This differential increase in cortical NA efflux in noncontingent subjects was no longer evident when the contingency shift procedure was repeated the next day. Cortical NA levels also increased in contingent subjects, although there was no indication on either day of testing that this response was specifically related to task performance. This is consistent with previous lesion studies showing a lack of effect of cortical NA depletion on baseline performance on this task (Carli et al., 1983; Cole and Robbins, 1992) as well as other attentional paradigms (McGaughy et al., 1997). In contrast, performance on the five-choice serial reaction time task produced sustained increases in cortical ACh efflux. Although significantly smaller in magnitude, this response was also observed in animals for which reward was made contingent on the performance of a second trained rat. These data indicate a neurochemical double dissociation of function that provides evidence for differential roles of NA and ACh systems in functions dependent on the prefrontal cortex. The discussion that follows addresses the implications of these data for theories of separable functions for cortical NA and $\mathrm{ACh}$ in attentional and cognitive processes.

\section{Noradrenergic mechanisms in arousal and attention}

The most compelling finding of this investigation is that NA release in the prefrontal cortex is specifically increased when the instrumental contingencies of a sustained attentional task are extinguished. The absence of a differential noradrenergic response on the second day of testing implies a high degree of behavioral specificity and highlights further the sensitivity of the LC noradrenergic system in detecting alterations in instrumental contingencies.

This result has implications for extending previous theories of LC noradrenergic function in arousal and attentional functions (Aston-Jones and Bloom, 1981; Robbins, 1997; Usher et al., 1999). In particular, it specifies a more general set of conditions that engage this system, which are distinct from merely aversive properties of stimuli or environmental conditions. Many sensory stimuli, both conditioned and unconditioned, are known to increase the activity of LC neurons and increase the release of NA in terminal fields (Aston-Jones and Bloom, 1981; Grant et al., 1988; Dalley et al., 1995; Feenstra, 2000). In addition, LC neurons in the rat have also been demonstrated to respond vigorously during reversal or extinction of a Pavlovian conditioning procedure (Sara and Segal, 1991). Recently, a state-dependent model of LC function has been described in which phasic and tonic changes in activity are hypothesized to promote focused and scanning attention, respectively (Aston-Jones et al., 1999; Usher et al., 1999). The protracted increase in cortical NA efflux in noncontingent subjects is certainly compatible with this latter tonic mode of operation. Thus, one interpretation of our results is that increased NA influx into the prefrontal cortex may signal a mismatch between instrumental actions and reinforcement. The resultant shift in attentional span may be an important feedback mechanism that accelerates contingency learning by disengaging non-reinforced behaviors in favor of new behavioral strategies that more reliably predict reinforcement. Support for this hypothesis stems from studies showing that lesions of the prelimbic cortex disrupt instrumental contingency learning (Balleine and Dickinson, 1998), and that 6-OHDA-induced depletion of forebrain NA can significantly delay the extinction of operant behavior (Mason, 1983). This finding is also compatible with more general evidence that the coeruleocortical NA system is especially involved in mechanisms of neural plasticity and learning imposed by new situations, whether in the domains of appetitive and aversive learning (Sara and Segal, 1991; Cahill et al., 1994; Robbins and Everitt, 1995; Brennan et al., 1998) or working memory (Franowicz and Arnsten, 1998).

\section{Cortical cholinergic function and visuospatial attention}

Much evidence has implicated a significant role of the basal forebrain cortical cholinergic system in attentional function. 
Thus, lesions of the cholinergic neurons of the basal forebrain produced using excitotoxins or the more selective cholinergic toxin 192-IgG saporin result in robust and persistent impairments in sustained attention (Muir et al., 1994; Voytko et al., 1994; McGaughy et al., 1996). Experiments in which ACh release has been measured in vivo in freely moving animals have also provided support for an involvement of the nucleus basalis cortical cholinergic pathway in attention (Sarter et al., 1996; Himmelheber et al., 2000; Passetti et al., 2000). However, these latter studies have revealed a more complex relationship between cortical cholinergic function and attentional performance than that anticipated from lesion studies. For example, Sarter et al. (1996) observed large increases in ACh efflux in the frontoparietal cortex simply by transferring subjects to an operant chamber designed to assess sustained attention. Nevertheless, subsequent performance and the introduction of a visual distractor to increase the attentional load produced additional, although somewhat smaller, increases in cortical ACh efflux. Sustained elevations in cortical ACh efflux have also been observed during stable performance on the five-choice serial reaction time task (Passetti et al., 2000). Critically, this response depended on the relative time engaged on the task rather than on the level of task difficulty. These results led us to speculate that the cortical cholinergic system may be involved in optimizing the sustained performance of sequences of orienting responses under control of salient external stimuli.

In this study we explicitly controlled reinforcement density, because food reward is known to elevate ACh release in the frontal cortex (Inglis et al., 1994). Thus, the observed dissociation in stimulated ACh efflux between contingent and noncontingent subjects cannot simply be because of differences in consummatory behavior. In addition, it seems improbable that differences in motor activity, which have been shown previously to affect cortical ACh efflux (Day et al., 1991), can fully account for the observed results. This conclusion is based on the clear disparity between actual performance and cortical ACh efflux in noncontingent subjects. Notably, cortical ACh efflux remained stable in these subjects over both days, yet the number of "runs" made between the apertures and magazine were more than twice as frequent on the first day. This evidence, together with previously presented arguments (see Passetti et al., 2000), strongly suggests that no simple relationship exists between motor activity and cortical ACh efflux on this task. If this assumption is correct, these data imply that a significant fraction of stimulated release of ACh measured in contingent subjects relates specifically to the cognitive demands of the task. This conclusion is supported by recent findings that intrabasalis infusions of the specific cholinergic toxin 192-IgG saporin, which substantially deplete cortical ACh efflux, produce profound and persistent impairments in visuospatial attentional performance on this task (J. McGaughy, J. W. Dalley, B. J. Everitt, and T. W. Robbins, unpublished observations).

It has been shown previously that either novel stimuli or stimuli that have acquired salience through classical conditioning increase cortical ACh release (Acquas et al., 1996). Repeated pre-exposure of these stimuli without consequence readily diminishes this response. The fact that performance on the five-choice task elicits sustained elevations in cortical ACh efflux with no evidence of habituation strongly implicates cortical ACh in aspects of attentional performance. Although cortical ACh efflux was attenuated in noncontingent subjects, it still increased relative to pretask levels. Conceivably, increased cortical ACh efflux in noncontingent subjects may have arisen from the failure to fully extinguish instrumental performance in these subjects. Additional studies with more protracted contingency extinction trials will be necessary to address this issue. An alternative hypothesis is that other stimuli in the environment, including auditory and visual cues from the hopper and tray light are now solely predictive of food delivery. Viewed in this way, the reduced level of $\mathrm{ACh}$ efflux in noncontingent subjects may reflect the reduced number of stimulus-bound response sequences required to obtain food reward. The greater degree of executive control required to coordinate the behavioral sequences necessary for contingent reinforcement, including visual search, detection, and response selection, may be responsible for generating the greater cortical output of ACh in these subjects.

\section{Conclusions}

This investigation is the first demonstration of a double dissociation between $\mathrm{ACh}$ and NA function in the prefrontal cortex during performance of a visuospatial attentional task. The results are consistent with the conclusion that the cortical cholinergic system is involved in aspects of established attentional performance. In contrast, the cortical noradrenergic system appears to be engaged when the predictive relationship between instrumental actions and reinforcement is degraded. These data suggest distinct but complementary roles of the cortical cholinergic and noradrenergic systems in optimizing attentional processing during situations of heightened arousal.

\section{REFERENCES}

Acquas E, Wilson C, Fibiger HC (1996) Conditioned and unconditioned stimuli increase frontal cortical and hippocampal acetylcholine release: effects of novelty, habituation, and fear. J Neurosci 16:3089-3096.

Aston-Jones G, Bloom FE (1981) Norepinephrine-containing locus coeruleus neurons in behaving rats exhibit pronounced responses to non-noxious environmental stimuli. J Neurosci 1:887-900.

Aston-Jones G, Rajkowski J, Cohen J (1999) Role of locus coeruleus in attention and behavioral flexibility. Biol Psychiatry 46:1309-1320.

Balleine B, Dickinson A (1998) Goal-directed instrumental action: contingency and incentive learning and their cortical substrates. Neuropharmacology 37:407-419.

Balleine B, Killcross S (1994) Effects of ibotenic acid lesions of the nucleus accumbens on instrumental action. Behav Brain Res 65:181-193.

Brennan PA, Schellinck HM, de la Riva C, Kendrick KM, Keverne EB (1998) Changes in neurotransmitter release in the main olfactory bulb following an olfactory conditioning procedure in mice. Neuroscience 87:583-590.

Cahill L, Prins B, Weber M, McGaugh JL (1994) $\beta$-Adrenergic activation and memory for emotional events. Nature 371:702-704.

Carli M, Robbins TW, Evenden JL, Everitt BJ (1983) Effects of lesions to ascending noradrenergic neurones on performance of a 5-choice serial reaction task in rats: implications for theories of dorsal noradrenergic bundle function based on selective attention and arousal. Behav Brain Res 9:361-380.

Cole BJ, Robbins TW (1992) Forebrain norepinephrine: role in controlled information processing in the rat. Neuropsychopharmacology 7:129-142.

Dalley JW, Mason K, Stanford SC (1995) Incremental changes in extracellular noradrenaline availability in the frontal cortex induced by naturalistic environmental stimuli: a microdialysis study in the freely moving rat. J Neurochem 65:2644-2651.

Dalley JW, Parker CA, Wulfert E, Hudson AL, Nutt DJ (1998) Potentiation of barbiturate-induced alterations in presynaptic noradrenergic function in rat frontal cortex by imidazol(in)e $\alpha 2$-adrenoceptor agonists. Br J Pharmacol 125:441-446.

Day J, Damsma G, Fibiger HC (1991) Cholinergic activity in the rat hippocampus, cortex, and striatum correlates with locomotor activity: an in vivo microdialysis study. Pharmacol Biochem Behav 38:723-729.

Feenstra MG (2000) Dopamine and noradrenaline release in the prefrontal cortex in relation to unconditioned and conditioned stress and reward. Prog Brain Res 126:133-163.

Franowicz JS, Arnsten AF (1998) The $\alpha$-2a noradrenergic agonist, guanfacine, improves delayed response performance in young adult rhesus monkeys. Psychopharmacology 136:8-14.

Granon S, Passetti F, Thomas KL, Dalley JW, Everitt BJ, Robbins TW (2000) Enhanced and impaired attentional performance after infusion 
of D1 dopaminergic receptor agents into rat prefrontal cortex. J Neurosci 20:1208-1215.

Grant SJ, Aston-Jones G, Redmond DEJ (1988) Responses of primate locus coeruleus neurons to simple and complex sensory stimuli. Brain Res Bull 21:401-411.

Himmelheber AM, Sarter M, Bruno JP (2000) Increases in cortical acetylcholine release during sustained attentional performance in rats. Brain Res Cogn Brain Res 9:313-325.

Huang T, Yang L, Gitzen J, Kissinger PT, Vreeke M, Heller A (1995) Detection of basal acetylcholine in rat brain microdialysate. J Chromatogr B Biomed Appl 670:323-327.

Inglis FM, Day JC, Fibiger HC (1994) Enhanced acetylcholine release in hippocampus and cortex during the anticipation and consumption of a palatable meal. Neuroscience 62:1049-1056.

Mason ST (1983) The neurochemistry and pharmacology of extinction behavior. Neurosci Biobehav Rev 7:325-347.

McGaughy J, Kaiser T, Sarter M (1996) Behavioral vigilance following infusions of 192 IgG-saporin into the basal forebrain: selectivity of the behavioral impairment and relation to cortical AchE-positive fiber density. Behav Neurosci 110:247-265.

McGaughy J, Sandstrom M, Ruland S, Bruno JP, Sarter M (1997) Lack of effects of lesions of the dorsal noradrenergic bundle on behavioral vigilance. Behav Neurosci 111:646-652.

Muir JL, Page KJ, Sirinathsingji DJS, Robbins TW, Everitt BJ (1993) Excitotoxic lesions of basal forebrain cholinergic neurons: effects on learning, memory, and attention. Behav Brain Res 57:123-131.

Muir JL, Everitt BJ, Robbins TW (1994) AMPA-induced excitotoxic lesions of the basal forebrain: a significant role for the cortical cholinergic system in attentional function. J Neurosci 14:2313-2326.

Passetti F, Dalley JW, O'Connell MT, Everitt BJ, Robbins TW (2000) Increased acetylcholine release in the rat medial prefrontal cortex during performance of a visual attentional task. Eur J Neurosci 12:3051-3058.

Paxinos G, Watson C (1982) The rat brain in stereotaxic coordinates. Sydney: Academic.

Rasmussen K, Jacobs B (1986) Single unit activity in the freely moving cat. II. Conditioning and pharmacological studies. Brain Res 371:335-344.

Robbins TW (1997) Arousal systems and attentional processes. Biol Psychiatry 45:57-71.

Robbins TW, Everitt BJ (1995) Central norepinephrine neurons and behavior. In: Psychopharmacology, 4th generation of progress (Bloom FE, Kupfer D), pp 363-372. New York: Raven.

Sara SJ, Segal M (1991) Plasticity of sensory responses of locus coeruleus neurons in the behaving rat: implications for cognition. Prog Brain Res $88: 571-585$.

Sarter M, Bruno JP (2000) Cortical cholinergic inputs mediating arousal, attentional processing, and dreaming: differential afferent regulation of the basal forebrain by telencephalic and brainstem afferents. Neuroscience 95:933-952.

Sarter M, Bruno JP, Givens B, Moore H, McGaughy J, McMahon K (1996) Neuronal mechanisms mediating drug-induced cognition enhancement: cognitive activity as a necessary intervening variable. Brain Res Cogn Brain Res 3:329-343.

Usher M, Cohen JD, Servan-Schreiber D, Rajkowski J, Aston-Jones G (1999) The role of locus coeruleus in the regulation of cognitive performance. Science 283:549-554.

Voytko ML, Olton DS, Richardson RT, Gorman LK, Tobin JR, Price DL (1994) Basal forebrain lesions in monkeys disrupt attention but not learning and memory. J Neurosci 14:167-186.

Zilles K (1985) The cortex of the rat. Berlin: Springer. 